\title{
Effect of Diazepam on Proliferation of Chondrocytes in Intermediate and Deep Zones of Patellar Articular Cartilage in Adult Male Mice
}

\author{
Anber Saleem 1,2,3 and Muhammad Yunus Khan ${ }^{4}$ \\ ${ }^{1}$ Mathematics and its Applications in Life Sciences Research Group, Ton Duc Thang University, Ho Chi Minh City, Vietnam \\ ${ }^{2}$ Faculty of Mathematics and Statistics, Ton Duc Thang University, Ho Chi Minh City, Vietnam \\ ${ }^{3}$ Department of Anatomy, Islamabad Medical and Dental College, Islamabad, Pakistan \\ ${ }^{4}$ Department of Anatomy, College of Physicians and Surgeons Pakistan, Islamabad, Pakistan
}

\begin{abstract}
Objective: To determine the effect of diazepam on proliferation of chondrocytes in intermediate and deep zones of degenerating patellar articular cartilage in Balb/c mice.

Study Design: Experimental study.

Place and Duration of Study: Department of Anatomy, College of Physicians and Surgeons Pakistan, Regional Centre, Islamabad, Pakistan, from June 2015 to May 2016.

Methodology: There were two groups of adult male mice as control group A and experimental group B. Group A having 90 mice was further divided into three subgroups having 30 mice in each subgroups. In subgroup A1 having 30 mice were treated normally. Subgroup A2 mice were kept immobilised for 20 days. Mice in subgroup A3 were given normal saline intraperitoneally during next 30 days of remobilisation and sacrificed. Among the mice in group $B$, normal saline was replaced with diazepam at the dose of $4 \mathrm{mg} / \mathrm{kg}$ for 30 days. Control subgroups and experimental group were compared. Data was analysed quantitatively using SPSS Version 16.

Results: Significant decrease in mean thickness of combined zone $(66.69 \pm 2.77 \mu \mathrm{m})$ and chondrocytes count $(5.61 \pm 0.76)$ were seen in subgroup A2 mice than subgroup A1 $(77.54 \pm 3.4 \mu \mathrm{m})$ and $(5.61 \pm 0.76)$, respectively $(p<0.001)$. Subgroup A3 showed significantly increased mean thickness $(95.45 \pm 5.17 \mu \mathrm{m})$ and chondrocytes count $(7.31 \pm 0.44)$ than subgroup A2 $(P<0.001)$. No significant increase in mean thickness $(96.46 \pm 4.94 \mu \mathrm{m})$ and chondrocytes count $(7.35 \pm 0.41)$ of group $B$ were seen than subgroup $A 3(p=0.01)$.

Conclusion: Diazepam administration does not stimulate proliferation of chondrocytes of combined intermediate and deep zones of degenerating articular cartilage by acting on GABA A receptors.
\end{abstract}

Key Words: Chondrocytes, Diazepam, GABA A receptors.

How to cite this article: Saleem A, Khan MY. Effect of diazepam on proliferation of chondrocytes in intermediate and deep zones of patellar articular cartilage in adult mice. J Coll Physicians Surg Pak 2019; 29(11):1025-28.

\section{INTRODUCTION}

Diazepam belongs to benzodiazepines drug class and is extensively prescribed for the management of anxietyrelated disorders. ${ }^{1}$ Anxiety-related disorders could result from decreased inhibitory signalling by GABA (Gammaminobuteric acid) which produces its effects by acting on GABA receptors. ${ }^{2}$ These receptors form chloride ion selective channels gated by GABA. Binding of GABA to GABA A receptors at the interface of alpha and beta subunits causes the increased conductance of chloride.3,4 GABA agonist drugs do not open the channels by themselves rather their binding to recognition sites results in

Correspondence to: Dr. Anber Saleem, Department of Anatomy, Islamabad Medical and Dental College, Islamabad, Pakistan

E-mail:dranbers@gmail.com

Received: December 06, 2018; Revised: July 12, 2019;

Accepted: August 22, 2019 conformational change in receptors such as to intensify the apparent affinity for channel gating by GABA at both agonist sites. 5,6 Therefore, diazepam being positive allosteric modulator of GABA A receptors enhances the effect of GABA by binding to GABA A receptors at high affinity allosteric sites located at interface of gamma and beta subunits. ${ }^{7}$ This agent increases the frequency of chloride channel opening produced by GABA. ${ }^{8}$ In addition to brain, GABA A receptors are also widely expressed in many peripheral non-neuronal tissues, $, 9,10$ which shows autocrine/ paracrine effects of GABA other than neurotransmitter effect.

Local distribution of GABA was found in the chondrocytes of hypertrophic and proliferative zones of rat tibial growth plate. ${ }^{11}$ Expression of GABA A receptors on chondrocytes of rat growth plate described the role of GABA in cell proliferation via activation of GABA A and GABA B receptors by their studies on ADTC5 mouse chondrogenic cell lineage. ${ }^{12}$ Chondrocytes are highly 
specialised cells of articular cartilage, which reside in extracellular matrix. This matrix consists of two main components - tissue fluid and structural molecules (proteoglycans, collagen, non-collagenous protein and glycoproteins) - which provide form and stability to the cartilage. ${ }^{13}$ Articular cartilage of mice is several cell layers thick and zones cannot be clearly distinguished. Chondrocytes of superficial zone chondrocytes are elliptical in shape and are arranged parallel to articular surface. Pair of round chondrocytes can be seen directing at an angle to articular cartilage in intermediate zone. In largest deep zone, large round chondrocytes are oriented at right angle to articular surface. Calcified zone is the transition from noncalcified cartilage to subchondral bone. A basophilic line, which specifies this demarcation, is called 'tide mark'. ${ }^{14}$

Studies on animal models have postulated that immobilisation induced several variations in articular cartilage including reduced thickness of cartilage, 15 and diminished number of chondrocytes. ${ }^{16}$ Alteration in articular cartilage of rats becomes obvious following immobilisation from 4-6 weeks. ${ }^{17}$

These changes heal up during remobilisation period to some extent as regeneration process is quite slow due to avascularity of articular cartilage. New agents are being introduced in research, which can speed up this process of regeneration by causing proliferation of chondrocytes of articular cartilage. The objective of this study was to determine the effect of diazepam on proliferation of chondrocytes in combined intermediate and deep zones of degenerating patellar articular cartilage in adult Balb c mice.

\section{METHODOLOGY}

This experimental study was conducted in Department of Anatomy, College of Physicians and Surgeons Pakistan, Regional Centre, Islamabad, Pakistan from June 2015 to May 2016. A total of 120 male Balb/c mice of age 8 weeks (wt 25-30 gms) were obtained from National Institute of Health $(\mathrm{NIH})$, Islamabad by random sampling technique. Mice with gross deformity or with cracked/removed plasters were excluded. All the mice were divided into two main groups, control $A$ and experimental B groups with further subdivisions of Group A into $A 1, A 2$ and $A 3$ having 20 mice in each. Day 0 was considered as starting day of experiment. Subgroup A1 contained normal adult male mice. In subgroup A2, the right knee joints were immobilised for 30 days using plaster of paris. The immobilisation procedure restricted the movement of right leg only. The mice in subgroup A3 were also immobilised using the same technique for same time period but were then remobilised for next 30 days. These mice were injected with normal saline intraperitoneally during remobilisation period. The mice of experimental B group underwent the same procedure of mobilisation and remobilisation for same time periods; but were given injection of diazepam at the dose of 4 $\mathrm{mg} / \mathrm{kg}$ intraperitoneally for 30 days of remobilisation. Control and experimental groups were kept under same conditions. Animals in subgroup A1 were kept in cages for 30 days without any intervention. Animals in subgroup A2 were sacrificed after 30 days of immobilisation. Animals in subgroup A3 and group B were sacrificed after 60 days (the periods of immobilisation and remobilisation).

Mice were euthanised with chloroform. Their knee joints were exposed by removing the overlying skin. In next step, a longitudinal incision was given, using the bone cutter to bisect the joint into equal halves also with a part of tibia and femur included. Surrounding muscles were cleared carefully, but quadriceps and patellar tendons were retained. Dissected specimens were preserved and decalcified in neutral buffered formalin and ethylene diaminetetraacetic acid (EDTA), respectively. Specimens were processed and sections of 7 micrometer thickness were made using microtome. Hematoxylin and eosin stains were used for routine histology. Statistical analysis of quantitative parameters expressed by mean \pm SD was done by using statistical package for social sciences (SPSS) Version 16. Students' t-test was used for the detection of any significant difference between the means of control and experimental groups. P-value of $\leq 0.05$ was considered significant.

\section{RESULTS}

Subgroup A2 showed the zones similar to mice of control normal subgroup (A1, Figure 1), but differences in morphology and arrangement of chondrocytes in these zones were observed. Hypertrophied cells with pale staining nuclei were mostly seen (19 out of 30 ) in subgroup A2 mice. The round chondrocytes were no longer arranged in columns, (Figure 2). Significant decrease in thickness of combined intermediate and deep zones of subgroup A2 was also seen when compared with subgroup A1 $(p<0.001)$. Significant decline in number of chondrocytes was observed in combined zone of subgroup $A 2$ in comparison with subgroup A1 $(p<0.001)$.

Chondrocytes in combined zones of articular cartilages of subgroup A3 mice were no more hypertrophied. Their perpendicular arrangement in deep zone, which was lost during immobilisation period, was not regained (Figure 3). Significant increase in thickness and number of chondrocytes of combined zone in subgroup A3 as compared to subgroup A2 was seen $(p<0.001)$. Combined zones in patellar articular cartilages of control (subgroup A3) and experimental (group B) mice were similar histologically (Figure 4) with no significant difference in thickness of zones and number of chondrocytes per unit area (Table I). 
Table I:

\begin{tabular}{l|c|c|c|c|c|c|c|c|c}
\hline Parameters & $\begin{array}{c}\mathrm{A} 1 \\
\mathrm{n}=30 \\
\mathrm{mean} \pm \mathrm{SD}\end{array}$ & $\begin{array}{c}\mathrm{A} 2 \\
\mathrm{n}=30 \\
\mathrm{mean} \pm \mathrm{SD}\end{array}$ & $\mathrm{p}$-value & $\begin{array}{c}\mathrm{A} 2 \\
\mathrm{n}=30 \\
\text { mean } \pm \text { SD }\end{array}$ & $\begin{array}{c}\mathrm{A} 3 \\
\mathrm{n}=30 \\
\text { mean } \pm \text { SD }\end{array}$ & $\mathrm{p}$-value & $\begin{array}{c}\mathrm{A} 3 \\
\mathrm{n}=30 \\
\text { mean } \pm \text { SD }\end{array}$ & $\begin{array}{c}\mathrm{B} \\
\mathrm{n}=30 \\
\mathrm{mean} \pm \mathrm{SD}\end{array}$ & $\begin{array}{c}\mathrm{p} \text {-value } \\
\mathrm{n}=30 \\
\text { mean } \pm \text { SD }\end{array}$ \\
\hline $\begin{array}{l}\text { Thickness of } \\
\text { combined zone }(\mu \mathrm{m})\end{array}$ & $77.543 \pm 3.4$ & $66.690 \pm 2.77$ & $<0.001$ & $66.690 \pm 2.77$ & $95.455 \pm 5.17$ & $<0.001$ & $95.455 \pm 5.17$ & $96.460 \pm 4.94$ & 0.465 \\
\hline $\begin{array}{l}\text { Number of } \\
\text { chondrocytes } \\
\begin{array}{l}\text { per unit area } \\
\left(1600 \mu \mathrm{m}^{2}\right)\end{array}\end{array}$ & $7.763 \pm 0.38$ & $5.619 \pm 0.76$ & $<0.001$ & $5.619 \pm 0.76$ & $7.317 \pm 0.44$ & $<0.001$ & $7.317 \pm 0.44$ & $7.354 \pm 0.41$ & 0.750 \\
\hline
\end{tabular}

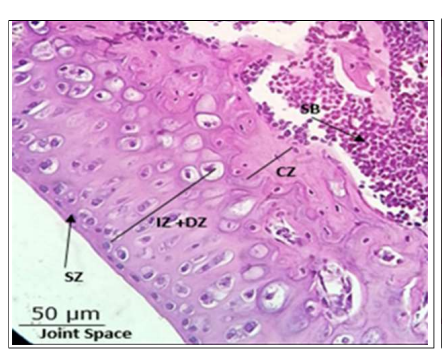

Figure 1: Photomicrograph of Hematoxylin-Eosin stained sections of articular cartilage of immobilised mouse showing hypertrophied cells with pale staining nuclei (subgroup A2). Scale bar $=50 \mu \mathrm{m}$. Magnification $=40 \mathrm{X}$.

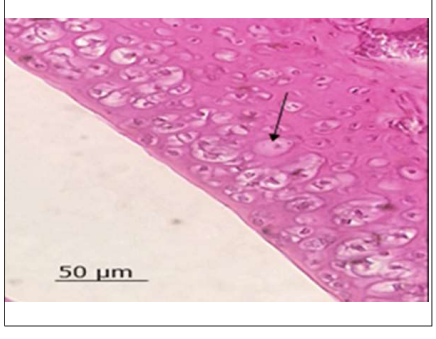

Figure 2: Photomicrograph showing the histology of articular cartilage of mouse belonging to subgroup A3 showing increased number of chondrocytes per unit area but loss of their perpendicular arrangement to articular surface. Scale bar $=50 \mu \mathrm{m}$ Hematoxylin-Eosin staining. manification $=40 \mathrm{X}$.

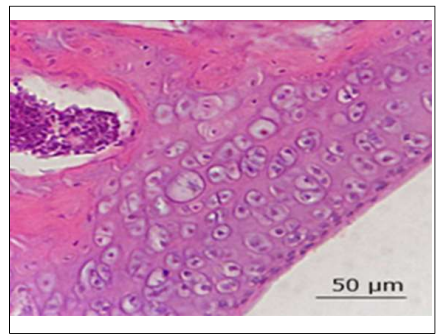

Figure 3: Photomicrograph showing the histology of articular cartilage of mouse belonging to subgroup A3 showing increased number of chondrocytes per unit area but loss of their perpendicular arrangement to articular surface. Scale bar $=50 \mu \mathrm{m}$ Hematoxylin-Eosin staining. Manification $=40 \mathrm{X}$.

\section{DISCUSSION}

Diazepam is a psychotropic agent used to treat many hyperactive neurological disorders like epileptic convulsions $^{2}$ but scientists are now emphasising on its effects other than neuropsychological ones by their studies on non-neural tissues etc. The results of our study obtained after application of statistical tests have shown that the diazepam has no stimulatory effect on proliferation of chondrocytes as predicted by insignificant increase in the thickness and number of chondrocytes in combined zones of articular cartilage. Osteoarthritis changes occurring in articular cartilage with age are now becoming challenge for scientists as there is no permanent treatment for that.

New researches are now being carried to explore advanced techniques that can reverse the osteoarthritic changes in articular cartilage. In this study, the researchers first induced degenerating osteoarthritic changes in articular cartilage of subgroup A2 by immobilising the knee joint for certain time period and then compared it with articular cartilage of normal mice of subgroup A1. Time period of immobilisation was limited to 30 days because degenerating changes appeared in articular cartilage up to this time period were reversible, indicating that chondrocytes still have ability to compensate the loss. ${ }^{16}$ Histological study of the sections of patellar articular cartilages of subgroup A2 showed significant decline in thickness and number of chondrocytes of combined zones as compared to their control (subgroup A1). These results are consistent with previous studies which showed marked reduction in thickness ${ }^{15}$ and number of chondrocytes after immobilisation. ${ }^{16}$ Drop in chondrocytes number may be one of the reasons underlying reduced thickness of the combined zone. Expressive compression forces may cause death of chondrocytes; thus diminishing the number of chondrocytes. In this study, chondrocytes of combined zone showed hypertrophy, and their nuclei had lost their staining ability. These changes can be narrated to the chondrocytes response towards the compressive forces as they are trying to repair the matrix by increasing their anabolic activity. Presence of hypertrophic cells in transitional zone was reported in rats after 2 weeks of rigid immobilisation in semiflexed position. 17 These results also showed derangement of columns of cells in this zone. This particular arrangement of cells is responsible for provision of strength to the articular cartilage. In this regard, we can say that immobilisation may also decrease the strength of articular cartilage.

According to some researchers, remobilisation is a natural physical factor that can reverse the mild degenerating changes in articular cartilage. 16 In this study, mice of subgroup A3 were remobilised to study the regenerative changes in articular cartilage. This led to marked increase in thickness and chondrocytes number of combined zones of articular cartilage in subgroup A3. This finding is not consistent to the results of some authors who described such loss of chondrocytes as an irreversible change. ${ }^{17}$

Diazepam was administered to experimental group $B$ to compare the rate of regenerative changes depicted by increase in thickness and number of chondrocytes in combined zones between subgroup A3 and group B. 
Slight increase in thickness and chondrocytes number in group B was seen; but that is not statistically significant. It may be due to the difference in experimental conditions as we have done in in vivo study. Increase in dose of diazepam may show some positive results; but we have restricted the dose because of its sedative effects.

\section{CONCLUSION}

Diazepam administration does not enhance the regenerative capability of articular cartilage during the remobilisation period by causing proliferation of degenerating chondrocytes through GABAA receptor activation.

ETHICAL APPROVAL:

This study was conducted after approval from the Institutional Review Board.

\section{CONFLICT OF INTEREST:}

Authors declared no conflict of interest.

\section{AUTHORS' CONTRIBUTION:}

SA: Conducted the research, analysed and interpretted the data.

MY: Supervised the study.

\section{REFERENCES}

1. Csacade $\mathrm{E}$, Kalali $\mathrm{AH}$. Use of benzodiazepines in treatment of anxiety. Psychiatry (Edgmont) 2008; 5:21-2.

2. Nemeroff $\mathrm{CB}$. The role of GABA in pathophysiology and treatment of anxiety disorder. Psychopharmacol Bull 2003; 37: 133-46.

3. Sigel E, Steinmann ME. Structure, function and modulation of GABA A receptors. J Biol Chem 2012; 287:40224-31.

4. Sigel E. Mapping of benzodiazepines recognition site on GABA receptors. Curr Top Med Chem 2002; 2:833-9.

5. Harvey RA, Clark MA, Finkel R, Rey JA, Whalen K. Pharmacology. $5^{\text {th }}$ edition. Philadelphia: Lippincott Williams and Wilkins 2012; p. 111-6.
6. Sigel E, Buhr A. The benzodiazepine binding site of GABA A receptors. Trends Pharmacol Sci 1997; 18:425-9.

7. Eqhbali M, Curmi JP, Gage MP. Hippocampal GABA A channel conductance increased by diazepam. Nature 1997; 388:71-6.

8. Akinci MK, Schofield PR. Widespread expression of GABA (A) receptor subunits in peripheral tissues. Neurosci Res 1999; 35:145- 53.

9. Tyagi N1, Lominadze D, Gillespie W, Moshal KS, Sen U, Rosenberger DS, et al. Differential expression of GABA A receptors and effects of homocysteine. Clin Chem Lab Med 2007; 45:1777- 84.

10. Tamayama T, Kanbara K, Maemura K, Kuro M, Watanabe M. Localization of GABA, GAD65, GAD67 in rat epiphyseal growth plate chondrocytes. Acta Histochem ET Cytochemica 2001; 34:201-6.

11. Tamayama T, Maemura K, Kanbara K, Hayasaki $H$, Yabumoto $Y$, Yuasa $M$, et al. Expression of GABA (A) and GABA (B) receptors in rat growth plate chondrocytes: Activation of the GABA receptors promotes proliferation of mouse chondrogenic ATDC5 cells. Mol Cell Biochem 2005; 273:117-26.

12. Iwamoto M, Ohta Y, Larmour C, Enomoto-Iwamoto M. Towards regeneration of articular cartilage. Birth Defects Res C Embryo Today 2013; 99:192-202.

13. Hughes LC, Archer CW, AP Gwynn I. The ultrastructure of mouse articular cartilage: Collagen orientation and implications for tissue functionality. A polarized light and scanning electron microscope study and review. Eur Cell Mater 2005; 9:68-84.

14. Jurvelin J, Kiviranta I, Tammi M, Helminen JH. Softening of canine articular cartilage after immobilization of knee joint. Clin Orthop Relat Res 1986; 207:246-52.

15. Hagiwara Y, Ando A, Chimoto E, Saijo Y, Ohmori-Matsuda K, Itoi $\mathrm{E}$. Changes of articular cartilage after immobilization in a rat knee contracture model. J Orthop 2009; 27:236-42.

16. Iqbal K, Khan Y, Minhas LA. Effect of immobilization and remobilization on superficial zone of articular cartilage of patella in rats. $J$ Pak Med Assoc 2012; 62:531-5.

17. Ando A, Suda H, Hagiwara Y. Reversibilty of immobilizationinduced articular cartilage degeneration after remobilization in rat knee joint. Tohoko J Exp Med 2011; 224:77-85. 